\title{
Selective solar absorber coating research at the CSIR (South Africa)
}

\author{
K.T. Roro $^{1 *}$, N.Tile ${ }^{1,2}$, B. Yalisi ${ }^{1,2}$, M. De Gama ${ }^{1}$, T. Wittes ${ }^{1}$, T. Roberts ${ }^{1}$, A. Forbes ${ }^{1,2}$ \\ ${ }^{I}$ CSIR-National Laser Centre, P.O. Box 395, Pretoria 0001, South Africa \\ ${ }^{2}$ School of Physics, University of KwaZulu Natal, Private Bag X54001, Durban 5000, South Africa \\ * Corresponding author. Tel: +27128413794, Fax: +27128413152,E-mail: KRoro@,csir.co.za
}

\begin{abstract}
A sol-gel technique has been established at a laboratory scale for low cost production of high efficient selective solar absorbers comprising a composite material of nano-structured carbon in a nickel oxide matrix. In order for these materials to be applied in real world scenarios it is necessary to extensively scale up the fabrication process to allow large area coatings. This can be done by adapting this sol-gel technique to large area deposition.

In this project, we are undertaking research and development activities for three-years to make a 'Lab to Large scale' transition in order to eventually integrate into existing solar collectors for low cost domestic water heating in a rural area for social good.

A spray coating technique has been used to deposit these $\mathrm{C} / \mathrm{NiO}$ coatings on aluminum substrates. Preliminary optical results have shown absorptance of up to $90 \%$. The preparation and characterization as well as the process towards developing a large-area solar selective coating for low cost domestic heating will be discussed.
\end{abstract}

Keywords: Sol-gel, Carbon-nickel oxide, Selective solar absorbers, Large-area.

\section{Nomenclature}

$\alpha_{\text {sol }}$ normal solar absorptance

$I_{\text {sol }}$ direct normal solar irradiance

$\varepsilon_{\text {ther }}$ normal thermal emittance

$I_{P} \quad$ Plank black body distribution

$R$ reflectance

\section{Introduction}

Hot water is required to maintain adequate sanitation and health. Often, water has to be boiled in order to make it safe for drinking. In rural Africa, the traditional fuel used for heating water is firewood, which produces smoke and is generally unsafe. Access to energy from fossil fuels such as oil, gas, and coal, by expanding grid electricity is either impractical or too expensive in these countries. There is therefore a clear need for low-cost and environmental friendly means of water heating.

Solar energy is a promising alternative energy source that can address these challenges. It is a resource readily available in every country around the world, and is not a threat to the environment through pollution or to the climate through greenhouse gas emission. As a matter of fact, most African countries have around 325 days of strong sunlight a year, on a verage, more than $6 \mathrm{kWh}$ energy per square meter a day [1]. Solar thermal energy is a technology for harnessing solar energy for thermal energy (heat). Solar thermal collectors for water heating use a spectrally selective surface that absorb sunlight and convert it to heat. High performing selective surfaces already exist in the market, but most of these products are produced using complicated manufacturing process and are expensive. The spectral selective surfaces are the most costly component of a solar thermal collector [2]. This means that if one reduces the price of selective solar absorbers one can hopefully reduce the cost of a solar thermal collector.

A sol-gel technique has been established at a laboratory scale for low cost production of high efficient selective solar absorbers comprising a composite material of nano-structured carbon in a nickel oxide matrix $[3,4]$. These coatings were deposited using a spin coater. Some of the 
advantages of this novel technique to fabricate carbon-metal oxide composite coatings are that it is simple and easy to control, utilizes readily available chemicals, does not require sophisticated equipments, the coatings can be deposited at ambient pressure conditions, and the process is low in material consumption. Therefore, the method is very promising for developing countries and could hopefully reduce the production costs for spectrally selective absorbers [5]. In order for these materials to be applied in real world scenarios it is necessary to extensively scale up the fabrication process to allow large area coatings. However, the spin coating process cannot be used for large area coatings. To succeed as a useful manufacturing technique, the specific deposition approach must be highly scalable while still producing films with the quality of laboratory deposition methods, e.g., spin coating. Spray deposition is historically scalable to large areas, and may also be applicable to deposit these $\mathrm{C} / \mathrm{NiO}$ composite coatings. Thus, large area coating can be done by adapting this sol-gel technique to large area deposition.

In this study, we will demonstrate the preparation of sol-gel $\mathrm{C} / \mathrm{NiO}$ nanocomposite coatings with reasonable optical properties on aluminum substrates by spray-coating technique and show the dependence of variation of the optical properties on different deposition process parameter.

\section{Experimental}

The absorbing films were coated on $r$ ough highly reflecting aluminum substrates. The substrates were cut into a $55 \times 55 \mathrm{~mm}^{2}$ size and cleaned before deposition. The pre-cleaning process involved cleaning the substrates with aqueous detergent and distilled water in order to remove the grease. Due to poor adhesion to the aluminum surfaces (uncleaned or cleaned with soap and water), the substrates were etched. The pre-cleaned substrates were thoroughly rinsed and dipped in a phosphoric acid bath at $60{ }^{\circ} \mathrm{C}$ for about 30 minutes or in an $\mathrm{HCl}$ bath kept at room temperature to remove the protective oxide layer. They were then thoroughly rinsed using distilled water to remove the acid. Finally they were blown dry with a $\mathrm{N}_{2}$ and coated immediately.

The preparation of the solution was adopted from a previous experiment [4]. The NiO precursor solution was prepared by dissolving an appropriate quantities of nickel acetate $\left[\left(\mathrm{NiAc}_{2}\right), \mathrm{Ni}\left(\mathrm{CH}_{3} \mathrm{COO}\right)_{2} .4 \mathrm{H}_{2} \mathrm{O}\right]$ in $50 \mathrm{ml}$ of absolute ethanol [(EtOH), $\mathrm{CH}_{3} \mathrm{CH}_{2} \mathrm{OH}$ ] followed by magnetic stirring at room temperature. An amount of diethanolamine [(DEA), $\mathrm{NH}\left(\mathrm{CH}_{2} \mathrm{CH}_{2} \mathrm{OH}\right)_{2}$ ] was added as a chelating agent. For the carbon precursor, sucrose was dissolved in doubly distilled water in the mass ratio 1:1 prior to mixing with the matrix precursor solutions. After a period of stirring appropriate quantity of polyethylene glycol[(PEG), $\left.\mathrm{HO}\left(\mathrm{CH}_{2} \mathrm{CH}_{2} \mathrm{O}\right) \mathrm{nH}\right]$, a structure directing template, was added to the $\mathrm{NiO}$ matrix precursor sol. The oxide and carbon precursor solutions were mixed and stirred again. The resultant solution was then further stirred until the formation of a sol. The final solution was poured into the spray gun and a conventional air compressor is used to eject the solution on top of the pre-cleaned aluminum substrates. The schematic representation of the spray deposition used during this study is shown in Fig. 1. A relatively low pressure (30-90 kpa) was used during deposition in order to ensure a fine atomization while preventing blowing off the droplets already deposited on the substrate. The distance of the spray gun from the substrate was kept at $50 \mathrm{~cm}$. In order to vary the thickness of the coatings, number of passes of the spray gun across the substrate was varied.

Once the substrates were spray coated, the samples were put into a tube furnace for pyrolysis and crystallization. The furnace temperature was raised to $450{ }^{\circ} \mathrm{C}$ at a $r$ ate of 
$20{ }^{\circ} \mathrm{C} \mathrm{min}{ }^{-1}$, maintained at that temperature for 60 minutes, and then left to cool to room temperature naturally. Nitrogen gas was continuously flown through the furnace throughout the heat treatment in order to maintain an inert atmosphere.

The near-normal spectral reflectance of the samples was measured in the $0.3-2.5 \mu \mathrm{m}$ wavelength range with a Perkin Elmer Lambda 900 spectrophotometer. A spectralon sample was used for reference spectrum measurements. A Bruker Tensor 27 spectrophotometer with a gold mirror reference was used to measure near normal reflectance in the 2.5-20.0 $\mu \mathrm{m}$ wavelength range. The reflectance measurements were used to calculate solar absorptance, $\alpha$, and the thermal emittance, $\varepsilon$, of the samples at $100^{\circ} \mathrm{C}$ using Eqs (1) and (2), respectively [6]:

$$
\begin{gathered}
\alpha_{\text {sol }}=\frac{\int_{0.3}^{2.5} I_{\text {sol }}(\lambda)(1-R(\lambda)) d \lambda}{\int_{0.3}^{2.5} I_{\text {sol }}(\lambda) d \lambda} \\
\varepsilon_{\text {ther }}=\frac{\int_{2.5}^{20} I_{P}(\lambda)(1-R(\lambda)) d \lambda}{\int_{2.5}^{20} I_{P}(\lambda) d \lambda} .
\end{gathered}
$$

The thermo-gravimetric analysis (TGA) was done on Perkin-Elmer TGA 4000 thermogravimetric analyzer. Approximately $100 \mathrm{mg}$ final mixture of $\mathrm{C} / \mathrm{NiO}$ precursor solution was placed in open $190 \mu \mathrm{l}$ alumina pan and heated from $25^{\circ} \mathrm{C}$ to $980{ }^{\circ} \mathrm{C}$ at a heating rate of $5{ }^{\circ} \mathrm{C}$ $\mathrm{min}^{-1}$ in $\mathrm{N}_{2}$ atmosphere (flow rate $50 \mathrm{ml} \mathrm{min}^{-1}$ ). The differential scanning calorimeter (DSC) results were collected on Mettler Toledo DSC 1 instrument. The surface morphology of the coatings was investigated using a ZEISS ULTRA plus FEG-SEM scanning electron microscopy. The Energy Dispersive Spectroscopy (EDS) analysis was done using a JEOLJSM 7500F Scanning Electron Microscope. Raman spectra were collected using a Raman spectroscopy (Jobin-Yvon T64000 spectroscope), equipped with an Olympus BX-40 microscope attachment. An $\mathrm{Ar}^{+}$laser $(514.5 \mathrm{~nm})$ with energy setting $1.2 \mathrm{~mW}$ from a Coherent Innova Model 308 was used as an excitation source.

\section{Results}

In order to determine the optimal temperature of heat treatment, the $\mathrm{C} / \mathrm{NiO}$ precursor solution was thermally analyzed by TGA and DSC techniques. Figure 2 displays a typical TGA and DSC curves for the $\mathrm{C} / \mathrm{NiO}$ precursor solution. It can be seen from the figure that the DSC curve shows 1 endothermic peak at $83{ }^{\circ} \mathrm{C}$ and 4 exothermic peak at $210{ }^{\circ} \mathrm{C}, 262{ }^{\circ} \mathrm{C}, 342{ }^{\circ} \mathrm{C}$ and $436^{\circ} \mathrm{C}$. TGA curve exhibit four weight loss stages: $53 \%$ the initial weight loss occurred 


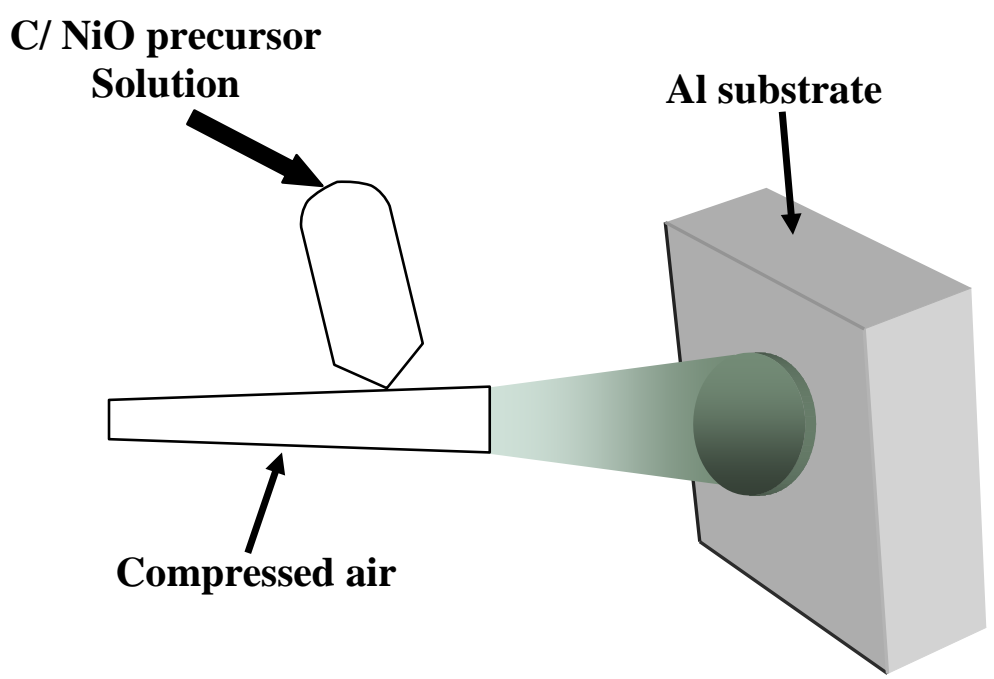

Fig. 1. A schematic diagram of the spray deposition technique used to deposit C/NiO nanocomposite coatings on Al surface.

31 and $57{ }^{\circ} \mathrm{C}, 10 \%$ between 75 and $144{ }^{\circ} \mathrm{C}, 15 \%$ between 144 and 295 and the final weight loss (13\%) between 295 and 341. The first weight loss was likely due to the evaporation of ethanol whereas the second and third was probably due to desorption of moisture and desorption of organic molecules, respectively. The fourth weight loss was most likely due to carbonization. Above $450{ }^{\circ} \mathrm{C}$ no noticeable weight loss has occurred. This stabilization of weight loss is accompanied by a distinct DSC exothermic peak at $437^{\circ} \mathrm{C}$ which indicates the crystallization of the composite material. It is therefore decided to anneal the samples at temperatures between $450{ }^{\circ} \mathrm{C}$ to $550{ }^{\circ} \mathrm{C}$. This choice has also been accompanied by the improvement of the optical absorption for samples heat treated in this temperature range (not shown).

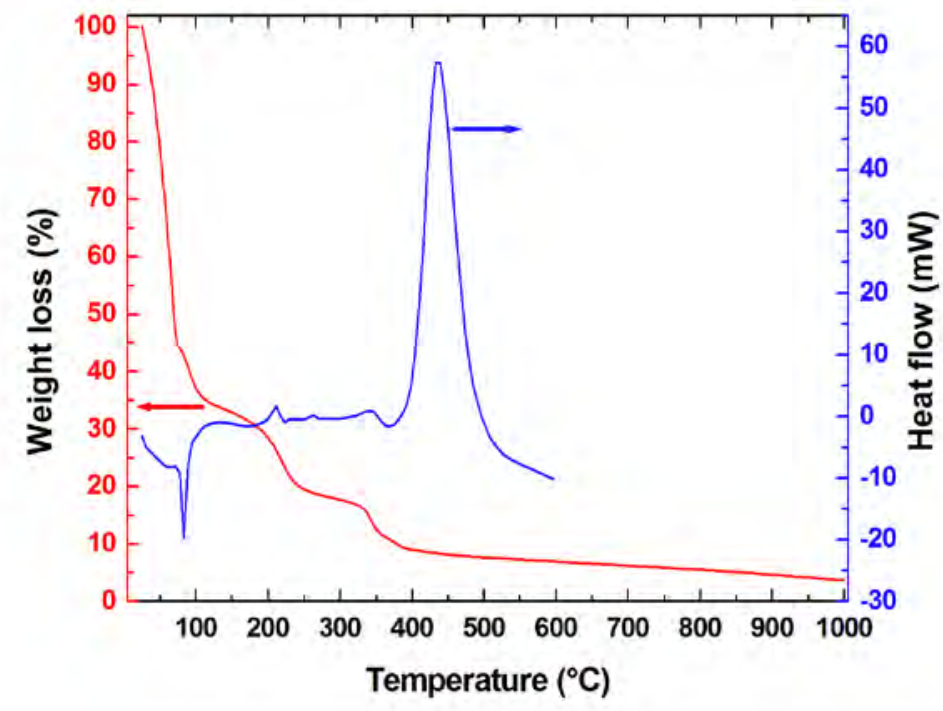

Fig. 2. Typical TGA and DSC spectra for C/NiO precursor solution. 

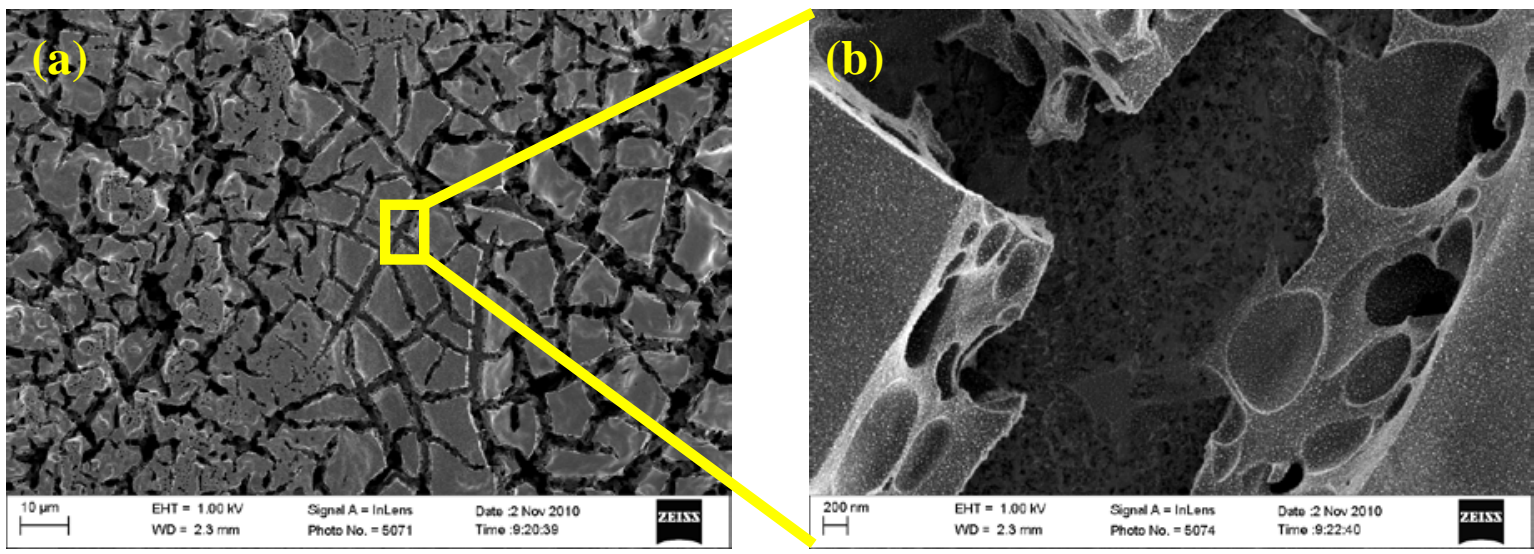

Fig. 3. (a) FE-SEM images of $\mathrm{C} / \mathrm{NiO}$ nanocomposite coated on aluminum substrate, (b) enlarged image.

Figure 3 (a) depicts a typical SEM image of a $\mathrm{C} / \mathrm{NiO}$ composite coating. The higher magnification image is shown in Fig. 3(b). As can be seen from Fig. 3 (a), the surface of the coating is uniform and cracked. The enlarged image (Fig 3(b)) shows that the coatings are porous. It is believed that the porosity of this film can produce high absorptance by multiple reflections [7]. The size distribution of the spherical particles in the coating is between 10 and $20 \mathrm{~nm}$.

The composition of $\mathrm{C} / \mathrm{NiO}$ composites was investigated using EDS (Fig. 4(a)). It reveals the presence of $\mathrm{C}, \mathrm{O}$, and $\mathrm{Ni}$, which confirms the existence of $\mathrm{NiO}$ nanoparticles in the coating. The Al signal originates from the substrate used for coating. The presence of carbon in these films is further evidenced by Raman studies conducted on these coatings. Figure 4(b) shows a typical Raman spectrum of the $\mathrm{C} / \mathrm{NiO}$ nanocomposite. The $\mathrm{D}$ band at $\sim 1350 \mathrm{~cm}^{-1}$ originates from amorphous carbon and structural defects; the $\mathrm{G}$ band at $\sim 1580 \mathrm{~cm}^{-1}$ is attributed to graphite structures, stems from tangential shearing mode of the carbon atoms [8-10]. The G' band at $\sim 2700 \mathrm{c} \mathrm{m}^{-1}$ is an overtone of the $\mathrm{D}$ band which indicates the long range graphite ordering. Higher order Raman modes are also visible in the region $2920-3220 \mathrm{~cm}^{-1}$.
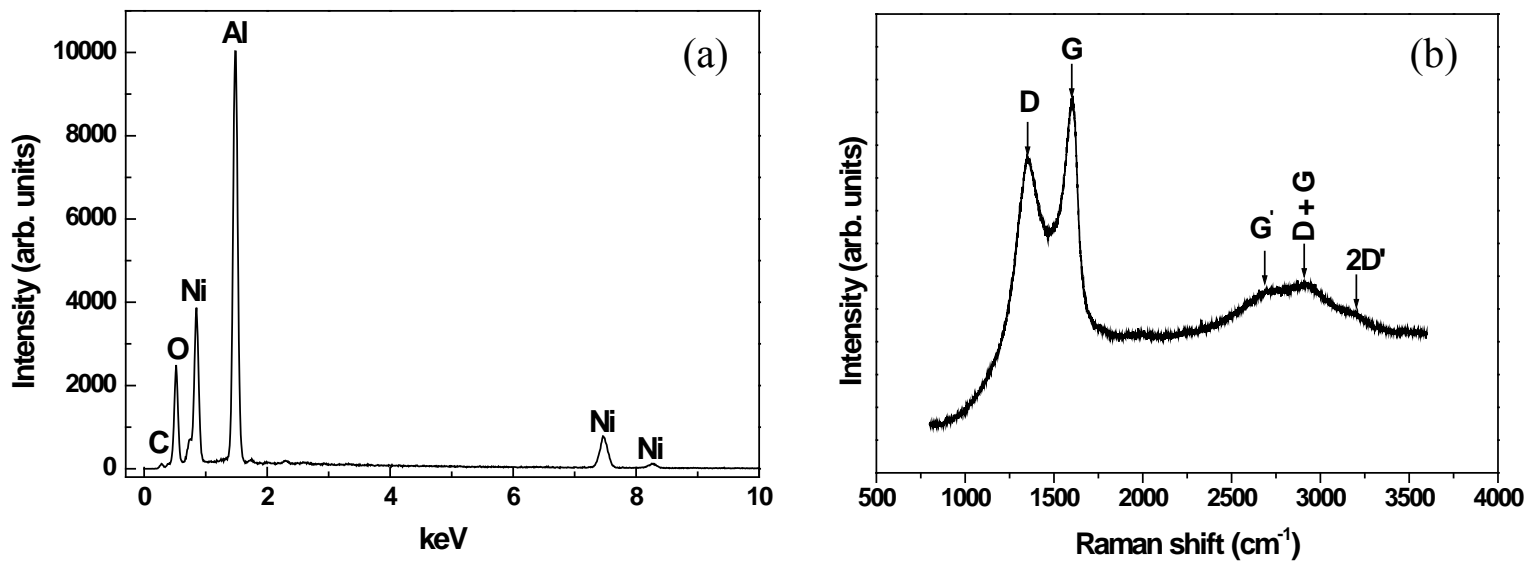

Fig. 4. (a) A typical EDS spectrum for C/NiO nanocomposite coated on aluminum substrate, (b) Raman spectra of the C/NiO nanocomposite coating. 


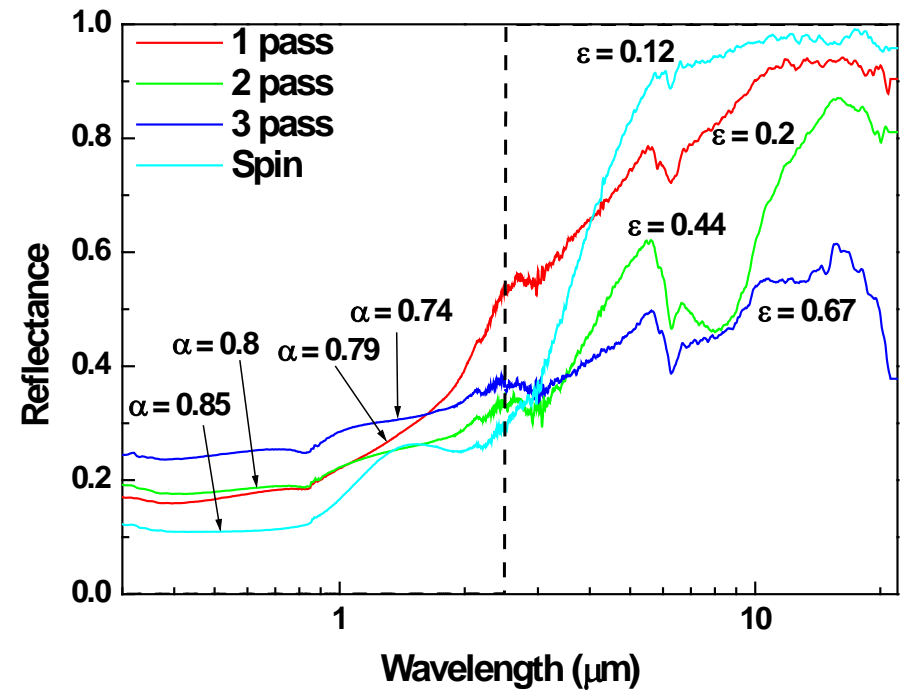

Fig. 5. The near normal reflectance spectra of $\mathrm{C} / \mathrm{NiO}$ nanocomposite deposited with different passes on aluminum substrate etched with $\mathrm{H}_{3} \mathrm{PO}_{4}$. The spectrum for spin coated samples is also included for comparison. The broken line represents the reflectance spectrum for an ideal selective solar absorber.

Figure 5 shows the reflectance spectra of spray deposited samples with different passes, together with a spin coated sample as a reference. The dips in the spectra at about $6.3 \mu \mathrm{m}$ are due to water absorption $\left(\mathrm{O}-\mathrm{H}\right.$ bending vibrations at $\left.1,600 \mathrm{c} \mathrm{m}^{-1}\right)[11,12]$. The $\mathrm{O}-\mathrm{H}$ bending vibrations for the spray deposited samples are much stronger than the spin coated samples. This implies that spray coated samples have higher emittance (lower reflectance) values.

The reflectance spectra of the $\mathrm{C} / \mathrm{NiO}$ nanocomposite deposited on a luminum substrate cleaned with $\mathrm{HCl}$ are presented in Fig. 6. It can be seen from the figure that the $\mathrm{O}-\mathrm{H}$ mode vibrations are also present in this $\mathrm{C}-\mathrm{NiO}$ samples. Although the solar absorptance values for some of the samples cleaned using $\mathrm{HCl}$ are better than the spin coated sample, they are highly emitting.

\section{Discussion}

The main reason for film cracking is due to film shrinkage because of solvent out gassing during the heat treatment [13]. Although it is minor, the thermal expansion rate difference between the coatings and the aluminum substrate can also contribute to the cracking during the cooling process [13]. According to Borström et al. [14], film homogeneity and propensity of film cracking is very important for solar absorbing thin films. The durability of the coatings will be severely affected due to infiltration of water and subsequent degradation of aluminum substrates. This clearly suggests that further study is necessary in order to reduce these cracks. 


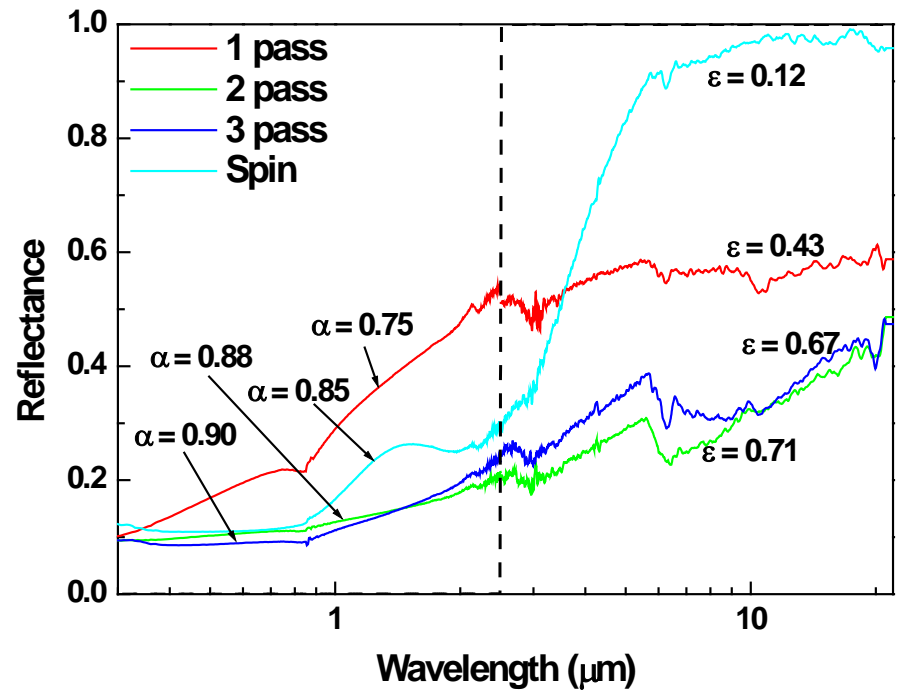

Fig. 6. The near normal reflectance spectra of $\mathrm{C} / \mathrm{NiO}$ nanocomposite deposited with different passes on aluminum substrate etched with $\mathrm{HCl}$. The spectrum for spin coated samples is also included for comparison. The broken line represents the reflectance spectrum for an ideal selective solar absorber.

In an effort to increase the absorptance of this single layer we have pretreated the substrate surface by etching with $\mathrm{H}_{3} \mathrm{PO}_{4}$ and $\mathrm{HCl}$. It is well known that the solar absorptance of selective absorber coatings can be enhanced by producing a textured surface [13]. The surface texturing of the aluminum surface with $\mathrm{HCl}$ enhanced the absorptance of the coating considerably (Fig. 6). However, the emittance of these coatings becomes worse. The magnitude of the surface roughness accompanying the pretreatment has to be much smaller than the peak thermal radiation wave length and comparable to the solar wavelength [14].

The production cost for a $1 \mu \mathrm{m}$ thick coating material for a lab scale is estimated to be $\mathrm{R}$ $0.35 / \mathrm{m}^{2}\left(\$ 0.05 / \mathrm{m}^{2}\right)$. This price can change significantly if the precursor materials are purchased in bulk. All other additional production costs and heat treatment were not estimated. The price for aluminium substrate is $\mathrm{R} 61.76 / \mathrm{m}^{2}\left(\$ 8.6 / \mathrm{m}^{2}\right)$. This implies that the material cost for the coating is very small compared to the substrate price. The material cost for a $100 \mathrm{~nm}$ thick coating for Ni-Alumina coatings were estimated to be $0.14 € / \mathrm{m}^{2}$ $\left(\mathrm{R} 1.4 / \mathrm{m}^{2}\right)$ [2]. It should be noted that the additional costs and heat treatment as well as transfer efficiency of the paint during spraying might slightly increase the cost.

Further research will focus on the optimization of the spray process parameters and the study of the durability of these coatings.

\section{Conclusion}

Spray deposition method was adapted for large-area deposition of sol-gel prepared $\mathrm{C} / \mathrm{NiO}$ nanocomposite coatings on aluminum substrate for selective solar absorber application. The coatings were made possible by using conventional air compressor. The number of passes was varied in order to optimize the thickness of the coatings. The performance of the sprayed samples was compared with the spin coated. The preliminary results have shown that the sprayed samples have comparable solar absorption properties with the spin coated suggesting that the sol-gel synthesized and sprayed $\mathrm{C} / \mathrm{NiO}$ composite films is very encouraging. 
The properties of these coatings will, however, require further developments before it could be integrated into an existing solar collector for low cost domestic water heating in a rural area for social good.

\section{References}

[1] G. Legros, I. Havet, N. Bruce, S. Bonjour, The energy access situation in developing countries, UNDP-WHO, 2009.

[2] T. Boström, E. Wäckelgård, G. Westin, Solar Energy 74, 2003, 497-503.

[3] G. Katumba, G. Makiwa, T. R. Baisitse, L. Olumekor, A. Forbes, and E. Wäckelgård, phys. stat. sol. (c) 5, No. 2, 2008, 549-551.

[4] G. Katumba, L. Olumekor, A. Forbes, G. Makiwa, B. Mwakikunga, J. Lu, E. Wäckelgård, Sol. Energy Mater. Sol. Cell. 92, 2008,1285- 1292.

[5] T. Boström, G. Westin, E. Wäckelgård, Sol. Energy Mater. Sol. Cell. 91, 2007, 38-43.

[6] J. A. Duffie and W. A. Beckman, Solar Engineering of Thermal Processes, JohnWiley \& Sons, New York, NY, USA, 1980.

[7] C. E. Kennedy, "Technical Report: Review of Mid-to-High-temperature Solar Selective Absorber Materials," National Renewable Energy Laboratory, prepared under Task No. CP02.2000, NREL/TP-520-31267, 2002.

[8] O. Lourie, H.D. Wagner, J. Mater. Res. 13, 2000, 2418.

[9] A.M. Rao, A. Jorio, M.A. Pimenta, M.S.S. Dantas, R. Saito, G. Dresselhous, and M.S. Dresselhaus, Phys. Rev. Lett. 84, 2000, 1820.

[10] A. Jorio, G. Dresselhaus, M.S. Dresselhaus, M. Souza, M.S.S. Danatas, M.A. Pimenta, A.M. Rao, R. Saito, C. Liu, H.M. Cheng, Phys. Rev. Lett. 85, 2000, 2617.

[11] G. Katumba, J. Lu, L. Olumekor, G. Westin, E. Wäckelgård, J. Sol-Gel Sci. Technol. 36, 2005, 33-43.

[12] A.V. Rao, R.R. Kalesh, G.M. Pajonk, J. Mater. Sci. 38, 2003,4407.

[13] T. Boström, S. Valizadeh, J. Lu, J. Jensen, G. Westin, E. Wäckelgård, J. Non-Cryst. Solids, 2010, doi:10.106/j.jnoncrysol.2010.09.023

[14] S. Sakka (Ed.), Handbook of Sol-gel Science and Technology, kluwer Academic Publishers, New York, 2005

[15] W.F. Bogaerts and C.M. Lampert, J. Mater. Sci. 18, 1983, 2847.

[16] F. Jahan, B.E. Smith, J. Mater. Sci. 5, 1986, 905-906. 